\title{
Nietzsche y Heidegger: verdad, valor y fundamento
}

\section{Nietzsche and Heidegger: truth, value and foundation}

\author{
Alonso Zengotita \\ https://orcid.org/0000-0002-9636-6503 - Email: alonsozengotita@gmail.com
}

\begin{abstract}
RESUMEN
Heidegger postula a Nietzsche como el último metafísico, en una línea que puede rastrearse hasta Platón y que históricamente ha desplegado un encubrimiento del ser. En el presente artículo se buscará abordar la crítica de Heidegger a Nietzsche con el objetivo de dar cuenta que la misma se sostiene desde un recorte de la relación valor-verdad nietzscheana. La hipótesis central sostendrá que, mientras Heidegger busca posicionar - a partir del recorte mencionadosu crítica en términos analítico-argumentativos, la misma se despliega más bien a partir del valor que cada autor le da a la verdad en términos de fundamento.
\end{abstract}

Palabras-clave: Nietzsche. Heidegger. Verdad. Valor. Fundamento.

\begin{abstract}
Heidegger posits Nietzsche as the last metaphysician, in a line that can be traced back to Plato and who has historically displayed a cover-up of being. In this article we will seek to address Heidegger's criticism of Nietzsche with the aim of realizing that it is sustained from a cut of the Nietzschean value-truth relation. The central hypothesis will maintain that, while Heidegger seeks to position - from the aforementioned clipping- his criticism in analytical-argumentative terms, it unfolds rather from the value that each author gives to the truth in terms of foundation.
\end{abstract}

Keywords: Nietzsche. Heidegger. Truth. Value. Foundation. 


\section{Introducción}

El modo en que Nietzsche caracteriza su filosofía como "platonismo invertido" (NIETZSCHE, 2008, p. 152, 7[156]) es según Vermal la instancia inicial desde la cual se despliega la perspectiva crítica de Heidegger: Nietzsche como el último metafísico'.

La lectura que realiza Heidegger sobre la filosofía nietzscheana - desplegada a lo largo de varios cursos, y compilada finalmente en el Nietzsche - ha sido comentada asimismo en múltiples ocasiones. Se encuentran - por hacer mención de algunas- aquellas de Vermal (2010), Véliz Rodríguez y Montagud Vicó (2014), Constante (2001) - y otras más clásicas, como aquellas de Krell (1976), Löwith (1946), o Thiele (1994) - las cuales abordan los cursos recorriendo de los distintos puntos fundamentales y realizando críticas diversas; por ejemplo, la reducción y ontologización que Heidegger hace de varios aspectos de la mirada nietzscheana, la intención, ya mencionada, de ponerse como el primer posmetafísico al hacer de Nietzsche el último metafísico, y también (trabajado centralmente en el artículo de Vicó y Rodríguez, y en el del propio Löwith) el intento de desligarse de sus relaciones con el nacionalsocialismo.

En el presente artículo se buscará abordar la crítica de Heidegger a Nietzsche con el objetivo de dar cuenta que la misma se sostiene desde un recorte de la relación valor-verdad nietzscheana. La hipótesis central sostendrá que, mientras Heidegger busca posicionar - a partir del recorte mencionado - su crítica en términos analítico-argumentativos, la misma se despliega más bien a partir del valor que cada autor le da a la verdad en términos de fundamento.

Para desplegar esto se abordará en primera instancia la interpretación que Heidegger hace del 'platonismo invertido', dando cuenta por una parte de cómo la identidad que postula respecto de los conceptos nietzscheanos de vida y voluntad de poder resulta falaz, y por otra de la obliteración que realiza de las condiciones de posibilidad que Nietzsche presenta respecto a la representación, con el fin de poner a éste en continuidad con la línea histórica que comienza con Platón. A continuación se articularán ambos desarrollos para dar cuenta de cómo la problematicidad de la relación valor-verdad gira en torno a la función misma de fundamento. Finalmente, en la conclusión se buscará establecer cómo la noción heideggeriana de que en Nietzsche 'el valor no le deja ser al ser' no ha de ser pensada - como lo propone Heidegger - en términos veritativos sino valorativos, lo cual permitirá a su vez especificar la divergencia de posiciones en respecto al nihilismo.

\section{Inversión, vida, voluntad de poder y condiciones de posibilidad}

En tanto - como se marcó - la crítica heideggeriana se ha trabajado ya en muchas ocasiones, se la enunciará de modo abreviado. En relación al carácter de 'platonismo invertido' Heidegger sostiene que '[e]n tanto este Arriba y Abajo determina la forma estructural del platonismo, él [Nietzsche] se mantiene esencialmente dentro.' (HEIDEGGER, 2000a, p. 233). Nietzsche establece:'[h]emos suprimido el mundo verdadero: ¿qué mundo queda? ¿El aparente quizá?... ¡Pues no! ¡Con el mundo verdadero también hemos suprimido el aparente!' (NIETZSCHE, 2007b, p. 57); al respecto, Heidegger dirá:

\footnotetext{
1 'La lectura de Heidegger no es una interpretación usual que intentaría presentar 'lo que Nietzsche realmente dijo', sino que lo interpreta desde un proyecto (...)' (VERMAL, 2010, p. 98), proyecto que lo pone a él, Heidegger, como el primer posmetafísico.
} 
[e]l mundo verdadero es el del devenir; el mundo aparente aquel que es estable y permanente. Los mundos verdadero y aparente han intercambiado lugares, rangos y formas. Pero en este intercambio e inversión la distinción entre mundo verdadero y aparente se mantiene. (2000a, p. 617).

No hay supresión sino inversión; lo verdadero será la voluntad de poder, lo aparente lo estable, ideático; así, según Heidegger “[v]oluntad de poder, devenir, vida y ser en el más amplio sentido significan en el lenguaje de Nietzsche lo mismo" (2000a, p. 394).

Ahora bien, Nietzsche sostiene:

(...) podría venir alguien que con una intención y un arte interpretativo antitéticos supiese sacar de la lectura de esta misma naturaleza, y en relación a los mismos fenómenos, cabalmente el triunfo tiránico, despiadado e inexorable de pretensiones de poder- un intérprete que os pusiese de tal modo ante los ojos la universalidad e incondicionalidad vigentes en toda'voluntad de poder' (...) Suponiendo que también esto sea nada más que interpretación - ¿y no os apresuraréis vosotros a hacer esta objeción?- bien, tanto mejor.' (2007a, p. 38).

Como marca Vattimo, la perspectiva de Nietzsche 'se reconoce en su carácter de fábula' (2002, p. 75). ¿Pero por qué esa fábula - por qué no otra? En orden de responder la pregunta se abordará la temática desde una óptica diversa a la heideggeriana: voluntad de poder y vida como no equivalentes.

Respecto a un escrito de Paul Reé, Nietzsche marca:

[e]n la obra antes mencionada (...) me referí a con ocasión y sin ella, a las tesis de aquél, no refutándolas -iqué me importan a mí las refutaciones!- sino, cual conviene a un espíritu positivo, poniendo, en lugar de lo inverosímil, algo más verosímil, y en lugar de un error, otro distinto. (2000, p. 16).

No se trata de refutar sino de poner otra cosa. En lugar de instancias como el yo, las Ideas, la res cogitans, el Espíritu, Nietzsche coloca a la vida. Y en vez de una vida caracterizada según la línea predominante de su tiempo - la vida como adaptativa al milieu ${ }^{2}$ - coloca una vitalidad en términos activos - como Wille zur Macht. Así entonces, nuevamente: ¿por qué esas fábulas?

Por lo visto hay que alargar mucho la mano para poder atrapar esa sutilísima verdad de que el valor de la vida no puede apreciarse. No puede ser apreciado por los vivos, porque es parte y hasta objeto del litigio, y no juez; ni puede ser apreciado por un muerto, por otras razones. (2007b, p. 25).

Frente al yo o la res cogitans - con carácter autorreflexivo, es decir, con capacidad de ponerse frente a sí mismos como objetos de completo análisis -, a las Ideas - con carácter de externalidad objetiva -, y al Espíritu - como síntesis de ambos aspectos-, la vida no resulta externa respecto al que valora y presenta opacidad en términos autorreflexivos - y por eso es lo único que no puede ser valorado. Asimismo: '[e]l'ser' - no tenemos para él otra representación ${ }^{3}$

\footnotetext{
${ }^{2}$ En referencia a la postura darwinista, con la que Nietzsche confronta en sus fragmentos Anti-Darwin. Para un desarrollo del tema cfr. Zengotita (2016).

3 El término mediador 'representación' (Vorstellung) podría conducir a la noción de que el 'vivir' (erleben) resulta secundario, o derivado, respecto de ese 'ser' (Sein). Otro fragmento de esa época ilustra adecuadamente el sentido con que Nietzsche utiliza aquí 'representación': 'Partiendo de una representación (Vorstellung) de la vida (que no es un querer-conservarse sino un querer-crecer), he lanzado una mirada sobre los instintos fundamentales de nuestro movimiento político, espiritual y social en Europa.' (2008, 2[179], p. 131). La representación implica aquí entonces la perspectiva central, rectora, a partir de la cual Nietzsche lanza su mirada: la vida como un querer-crecer. Al estipular Nietzsche que del ser no se tiene otra representación que el vivir, está mar-
} 
más que'vivir' - ¿Cómo puede entonces'ser'algo muerto?' (2008, 2 [172], p. 130). Al ser el viviente parte misma de la vida y no pudiendo producir un distanciamiento que permita la autorreflexión, lo representativo ha de producirse a partir de dicha ligazón vital; así la perspectiva jamás es pura sino parcial - contaminada necesariamente de vida. Esto implica la propia noción de ficción: no pudiéndose captar la vida de modo completo - no pudiéndose valuar -, el punto ciego producto de esto necesariamente despliega la generación de fábulas. Así se justifica la elección de la fábula que es la vida: abordar la necesaria representatividad creativa desde dicho concepto resulta-usando el término nietzscheano - más'verosímil'que hacerlo desde instancias que implican objetividad, externalidad, permanencia.

¿Qué sucede con la elección de la fábula que es la Wille zur Macht? Esta, como se marcó, se despliega desde la confrontación con la perspectiva vital predominante de sus tiempos:

(...) a mí me parece que se han enseñoreado ya incluso de toda la fisiología y de toda la doctrina de la vida, para daño de las mismas, como ya se entiende, pues le han escamoteado un concepto básico, el de la auténtica actividad (Aktivität). En cambio, bajo la presión de aquella idiosincracia se coloca en el primer plano a la 'adaptación' (Anpassung), es decir, una actividad de segundo rango, una mera reactividad (Reaktivität), más aún se ha definido la vida misma como una adaptación interna, cada vez más apropiada, a las circunstancia externas (Herbert Spencer). Pero con ello se desconoce la esencia de la vida, su voluntad de poder; con ello se pasa por alto la supremacía de principio que poseen las fuerzas espontáneas, agresivas, invasoras, creadoras de nuevas interpretaciones, de nuevas direcciones y formas, por influjo de las cuales viene luego la 'adaptación'; con ello se niega en el organismo mismo el papel dominador de los supremos funcionarios, en los que la voluntad de vida aparece activa y conformadora.' (2000, p. 12).

Según Nietzsche, la perspectiva vital con la que confronta es una caracterización moderna de los valores occidentales que hace siglos hacen tienden a la vida decadente partiendo del platonismo y continuándose en el cristianismo. 'Ironía ante lo que creen al cristianismo superado por las modernas ciencias naturales. Los juicios de valor cristianos no están en absoluto superados por ellas. 'Cristo en la cruz' es el símbolo más sublime - aún hoy.' $(2008,2[96]$, p. 91). Tanto las capacidades activas como las reactivas hacen a la dinámica vital, pero la perspectiva darwinista-spenceriana - como 'sombra de Dios' - extrajo a las activas de la vida y las puso en su afuera. Ese afuera, ese medio que entonces posee a las potencias activas, fuerza a la vida a adaptarse para poder sobrevivir. La vida natural del viviente no es otra entonces que aquella del esfuerzo, el sacrificio, la culpa, la humildad - es decir los valores cristianos, funcionales a un hipertrófico Medio (o Dios). La mirada moderna propia de la perspectiva darwinista no es así sino una cobertura cientificista de los mismos valores que han empequeñecido a la vida desde siglos.

Como se mencionó, según Heidegger la ficcionalidad propia de lo vital y la fábula que pone a la vida como Wille zur Macht son pensadas como lo mismo -'al pensamiento nietzscheano de la voluntad de poder lo denominamos su pensamiento único.'(2000a, p. 389). Así, lo opaco y parcial que hace a lo vital en tanto despliegue ficcional es obliterado. Heidegger toma la afirmación nietzscheana - 'El 'ser' - no tenemos para él otra representación más que 'vivir' ¿Cómo puede entonces 'ser' algo muerto?' (2008, 2 [172], p. 130) - en orden de sostener que Nietzsche no logra salir de la representatividad como $\mathrm{tal}^{4}$, al no inquirir respecto a sus condiciones de posibilidad (cfr. HEIDEGGER, 2004, p. 110) - lo que implicaría en Heidegger

cando que es a partir de la perspectiva del vivir que puede pensarse ese ser, o más bien, que no hay un ser por detrás de la perspectiva del vivir - y por ende, no puede pensarse el ser de algo muerto.

4 Heidegger hace la misma afirmación sobre Leibniz. 
abordar la verdad en términos de ocultamiento y desocultamiento. Pero aquello obliterado por Heidegger es justamente lo que permite dar cuenta de las condiciones de posibilidad nietzscheanas respecto a la representatividad; la parcialidad y opacidad vitales son el punto de partida estructural de la dinámica ficcional - es decir, que toda perspectiva posible no pueda darse sino desde la representatividad. Al no poder darse una objetualidad en tanto tal por la naturaleza misma de dicho punto de partida, el valor es completado vía ficción - y entonces no hay algo del orden del ser que resulte re-presentado. Heidegger sostiene:

[l]a metafísica de Nietzsche no se limita únicamente a interpretar el ser a partir del ente en la orientación impuesta por la voluntad de poder, concebida como un valor, sino que llega incluso a interpretar pensar esta voluntad como principio de una nueva institución de valores. En este sentido se le revela también como aquello que hace posible la superación del nihilismo. Y es entonces justamente cuando el hundimiento absoluto de la metafísica en la inautenticidad del nihilismo es evidenciado por la voluntad misma de trascenderlo. De tal modo ocurre esto, que el hundimiento disimula su propia esencia, y así, bajo la forma de una reducción, no hace otra cosa que trasponer el nihilismo al plano del eficaz desencadenamiento de su de-esencia (Unwesen). (2000b, p. 301).

El ser se interpreta desde el plano del ente: desde una línea analítica similar a la tomada respecto a la representación, Heidegger caracteriza al pensamiento de Nietzsche como eminentemente metafísico al ser una continuación de la historia filosófica del olvido del ser. Si vida y voluntad de poder son lo mismo y vida y ser también, el ser está pensado desde lo propio de un ente al cual Nietzsche valoriza particularmente - la vida. De este modo 'la transvaloración de Nietzsche es en el fondo el repensar en términos de valor todas las determinaciones del ente.'(2000b, p. 95). Si la superación del nihilismo implica en Nietzsche la producción de valores nuevos, que esto se dé puramente desde el ente da lugar a lo contrario - el hundimiento en el nihilismo.

En este punto se produce la articulación entre la crítica a la representatividad y el carácter metafísico. No abordar las condiciones de posibilidad de la representación implica dejar de lado a la verdad como ocultamiento y desocultamiento del ser. Concebir al ser como voluntad de poder - que es lo mismo que vida- pone al ejercicio valorativo desde el plano del ente como lo fundamental; así, existe un recubrimiento absoluto del plano del ser por algo que se quiere poner como ser pero presenta todas las características propias del ente. Desde aquí se da la inversión de efecto: no hay superación sino exacerbación del olvido del ser - llegando a la deesencia (Unwesen). De este modo, en su carácter de recubrimiento total '[e]l valor no le deja ser al ser'. (2000b, p. 102). Carácter metafísico y representatividad sin pregunta por sus condiciones de posibilidad se articulan en la de-esencia - el olvido del ser.

Ahora bien, como se desarrolló, Nietzsche despliega condiciones de posibilidad de la representatividad, mas Heidegger las oblitera - habilitando la equiparación entre vida, voluntad de poder, ser y devenir ${ }^{5}$, fundamentando el caracterizar como metafísico a Nietzsche y permitiendo desarrollar su interpretación del 'platonismo invertido'. En efecto, al identificar vida y Wille zur Macht estructuralmente se posibilita diferenciar entre devenir y permanencia - el Abajo y Arriba. Si - como se analizó - no se abordan las condiciones de posibilidad de la vida - si no se la reconoce como un ente separado del plano del ser- se recurre en el mismo error platónico: la vida, como las Ideas, son un ser en sí. Nietzsche entonces pone a un ente particular,

\footnotetext{
${ }^{5}$ Es lo que también permite a Heidegger caracterizar a la vida como principio único de puro acrecentamiento, afirmando que la filosofía de Nietzsche 'en seguro de antemano la dominación técnica moderna' (2000b, p. 302). Nietzsche como el despliegue glorioso de la tecnociencia, el Übermensch, el técnico supremo.
} 
una representación caracterizado particularmente - la vida como voluntad de poder - como el ser mismo, y entonces se lo puede distinguir de una apariencia.

Por el contrario el análisis llevado a cabo, al dar a la vida y a la voluntad de poder su especificidad propia, permite deshacer dicha equiparación. Vida y voluntad de poder no son iguales: la opacidad y parcialidad de la vida como tal da cuenta de la ficcionalidad, es decir, de las condiciones de posibilidad de la representación; la voluntad de poder es una fábula particular que confronta con una determinada perspectiva axiológica - la que ha regido la civilización occidental. Si el movimiento heideggeriano ha sido soldar vida y voluntad de poder para luego transferir esa duplicidad a la conformación de un Arriba y Abajo platónico - la verdad del devenir y la apariencia de lo permanente - el deshacer la mismidad de vida y voluntad de poder deshace entonces la duplicidad platónica: el devenir y la representación pierden su carácter de verdaderos como ser en sí - hay allí condiciones de posibilidad.

Desde este punto de vista - fábula en tanto que tal - la noción heideggeriana de la equiparación entre vida, ser, devenir y voluntad de poder no se sostiene, y la continuidad del Arriba y Abajo platónico - diferencia eminente entre apariencia y verdad - tampoco.

\section{Fundamento y verdad: el Ursprung como de-esencia}

Si es en 1936 que, en conjunto con su primera conferencia sobre Hölderlin, Heidegger dedica buena parte del año a dictar cursos sobre Nietzsche, ya desde comienzos de la década del 30 comienza a desplegarse el Kehre en su filosofía. En este giro en su perspectiva, Heidegger busca dar cuenta de una instancia más originaria respecto a lo planteado en Ser y tiempo, el Ereignis, un ocultamiento que precede a la alétheia y resulta su condición de posibilidad. En sus últimas enseñanzas, el Ereignis es concebido como aquello que funge como condición de posibilidad misma del ser y del tiempo; la Lichtung como apertura de un claro es lo que posibilita que aparezca la luz, que el ser y el tiempo se den a la presencia (Anwesenheit) y al presente (Gegewärtigung). El Ereignis como lo que nunca viene a la presencia, como lo que es condición de posibilidad de lo presencial y presente. En particular en Zum Ereignis-Denken, Heidegger articula a la esencia misma de la verdad con el preguntar: la pregunta por el ser da cuenta de que el mismo se proyecta desde el ocultamiento, volviéndolo como tal algo sobre lo que no es posible determinar una única respuesta - es decir, volviéndolo algo que permanece en sí mismo en cuestión, respecto de lo cual hay que estar en continua escucha. Es desde esta capacidad cuestionante del ser humano que el ser puede desplegarse al dar como esencia de su verdad al ocultamiento - como no sucede en el caso de otros vivientes ${ }^{6}$. Heidegger entonces afirma:

[p]oder preguntar - significa pararse en la verdad como tal - en lo abierto para lo que se oculta a sí mismo; y justamente en el preguntar es plenamente soportada esta esencia de la verdad: el preguntar inaugura y va a lo abierto y se comporta y se sostiene en sí frente a lo que se oculta. (2013, p. 481).

Al buscar dar cuenta de la continua puesta en cuestión, ¿no cumple entonces el ocultamiento en la verdad heideggeriana el mismo papel que la noción de ficcionalidad en Nietzsche, en tanto lo que hay no es sino un conjunto de interrelaciones cambiantes - y por ende, no una cosa en sí? ¿No es la ficcionalidad la verdad de las cosas para Nietzsche?

\footnotetext{
${ }^{6}$ Como marca Davis, 'el ser se apropia del Dasein de modo que, en su despliegue, esencialmente se da en y a través de los patrones de producción de sentido del Dasein.'(2010, p. 146).
} 
El punto está en el papel que juegan el ocultamiento y la ficcionalidad. Mientras que para el primero el ocultamiento funge como fundamento que da lugar a una verdad, para el segundo la ficcionalidad no da lugar al fundamento, y por ende no permite el sostenimiento de la verdad. Lo que allí se despliega es una dinámica estructural diversa: en tanto el ocultamiento funge como fundamento - en tanto permite fundar verdad - establece una diferenciación de planos - dispuesta por Heidegger, justamente, en términos de lo óntico y lo ontológico. Por el contrario, en Nietzsche la ficcionalidad de las cosas no conduce sino a la equivalencia ontológica de toda interpretación - no hay otro plano sino aquel en el cual se juegan los procesos interpretativos ${ }^{7}$. Esta equivalencia produce, justamente, que sea vía lucha que se produzca la prevalencia de una perspectiva. La propia vida presenta dicha dinámica, incluso de modo interno:

[I]a contraposición de las pasiones, la duplicidad, la triplicidad, la multiplicidad de las'almas en un único pecho's: muy insano, ruina interna, disgregante, delatando e intensificando una disensión y un anarquismo internos: a no ser que una pasión finalmente acabe por dominar. Retorno de la salud - (2008, 14[157], p. 584).

Lo saludable se alcanza cuando desde el conflicto una perspectiva acaba por imponerse. Ahora bien, esa salud ¿supone entonces la pérdida de toda diferencia interna?

La pasión dominante, la cual lleva consigo incluso la forma suprema de la salud en general: aquí se alcanza de manera óptima la coordinación de los sistemas internos y el concurso de sus trabajos al servicio de una unidad - pero ¡esto es prácticamente la definición de la salud! (2008, 14[158], p. 584).

No es borrar diferencias, sino coordinarlas en una unidad desde una perspectiva preponderante nacida de la lucha - no de una instancia original que determine dicha preponderancia.

¿Pero esta concepción vital no está justamente presuponiendo una verdad, la de la ficcionalidad misma como fundamento? Allí aparece nuevamente la respuesta nietzscheana: 'Suponiendo que también esto sea nada más que interpretación - ¿y no os apresuraréis vosotros a hacer esta objeción? - bien, tanto mejor'. (2007a, p 38). Lo que Nietzsche busca aquí desplegar es que si se parte de la búsqueda de la verdad se obtiene un regressus ad infinitum que impide la obtención de cualquier fundamento; en efecto, se puede afirmar que la ficcionalidad misma es interpretación, y que esta interpretación de la interpretación lo es asimismo, y así... La búsqueda en términos veritativos no presenta punto de detención posible, y por ende no conduce sino al continuo hundimiento en sí misma: desde la verdad no es posible construir nada - y por ello equipara voluntad de verdad con impotencia de la voluntad de crear $^{9}$. Si para Heidegger el hundimiento es concebido como 'de-esencia' (Unwesen), es decir, el corrimiento total respecto del plano del ser - y por ende la pérdida de toda relación con la verdad, al hacer de todo interpretación - para Nietzsche el hundimiento supone la continua búsqueda - la continua escucha - respecto de un plano del ser en términos de verdad. Lo que Nietzsche propone es entonces - vectorialmente hablando- el cambio de sentido: no es un ir hacia atrás,

\footnotetext{
7 Pero, ¿no se había diferenciado un plano de la ficcionalidad, el de la vida, respecto a aquel de la voluntad de poder? Justamente lo que hace dicho plano es devolver toda dinámica vital al plano de la lucha, sin proveer de fundamento alguno para erigir verdad. Este punto será retomado más adelante en términos de la dinámica veritativa como regressus ad infinitum.

8 Alusión al libro I del Fausto de Goethe.

9 'La creencia en el mundo que debería ser, es, existe realmente, es una creencia de improductivos que no quieren crear un mundo tal como debe ser. Lo ponen como existente, buscan los medios y caminos para llegar a él. 'Voluntad de verdad' como impotencia de la voluntad de crear. (NIETZSCHE, 2008, 9[60], p. 250).
} 
en búsqueda de la verdad - para desde allí, fundadamente, avanzar - sino el construir hacia delante de modo directo, en términos de valor. No se trata de que Heidegger no busque avanzar, sino que desde Nietzsche el movimiento de búsqueda de fundamento invalida todo posible avance: la necesidad de fundamentar es eminentemente metafísica.

¿Pero la genealogía nietzscheana no implica justamente la búsqueda de un origen, de una instancia que sirva como fundamento? Por el contrario, el trayecto genealógico no sólo implica la generación de una búsqueda hacia atrás en términos desenmascaradores - dando cuenta de que 'las verdades son ilusiones de las que se ha olvidado que lo son (...)' (NIETZSCHE, 2003, p. 208) - sino que implica a su vez el recorrer ese trayecto hacia delante en términos de mostrar a la verdad como producto ${ }^{10}$. En este sentido, Foucault realza la distinción entre la inquisición en pos un origen (Ursprung) o de un comienzo (Herkunft), articulada con la búsqueda genealógica: la primera implicaría un 'levantar todas las máscaras, para develar finalmente una identidad primera' (p. 147), mientras que la segunda, propia del camino genealógico, permite 'descubrir que a la raíz de aquello que conocemos y de aquello que somos no existen la verdad y el ser, sino la exterioridad del accidente.' (FOUCAULT, 1971, p. 148).

Desde esta perspectiva estructural, ¿qué es entonces el valor? Es la no articulación, en términos de fundamento, entre la ficcionalidad y la elaboración de perspectivas. Mientras que en Heidegger existe una conexión entre el plano del ser y el plano óntico, que permite dar cuenta de la verdad en función del ocultamiento y el desocultamiento, en Nietzsche no existe conexión alguna que permita establecer, ontológicamente, una perspectiva como la verdadera; la dinámica entonces es la de la lucha y no la de la escucha.

En Nietzsche, así, el problema no pasa por la verdad misma - pues es ilusión - sino por la dinámica que conlleva la voluntad de verdad, a saber, el hallar una conexión entre algo puesto a la base y lo que de allí se habrá de desplegar. El recorte que Heidegger produce respecto a las relaciones de verdad-valor en Nietzsche queda así explicitado: no se trata de que en Nietzsche no se aborden las condiciones de posibilidad, sino que dicho abordaje desnaturaliza su carácter de fundamento. En el hundimiento de la verdad en sí misma, la ficcionalidad no valida aquella como instancia a partir de la cual desplegar construcción.

\section{Conclusión}

Heidegger establece que Nietzsche mantiene un platonismo invertido - y por ende resulta un metafísico - al hacer al mundo verdadero el del devenir y al aparente aquel de la estabilidad. Como sinónimos del mundo verdadero quedan el devenir, la voluntad de poder, la vida, los cuales son parte del plano óntico, en el cual Nietzsche quedaría atrapado al concebirlo desde la representatividad, sin preguntarse por sus condiciones de posibilidad. Como - según sostiene Heidegger - pensar desde la voluntad de poder como verdad implica el traducir todo

\footnotetext{
${ }^{10}$ Staten, en su artículo 'The Problem of Nietzsche's Economy', señala refiriéndose al 'más allá' nietzscheano en relación a los valores del bien y el mal, que 'aunque el bien y el mal han sido tachados, la carga esencial de la 'moralidad' ha sido en un sentido transferida intacta en las nuevas categorías de fuerza y debilidad' (1989, p. 75). Al plantear dicha transferencia, Staten pierde de vista el carácter de producto del que Nietzsche provee a -entre otros- los valores. Ahora bien, la búsqueda genealógica de Nietzsche tiende a desacralizar las concepciones -cristianas- del bien y el mal, de modo de presentarlas como pasibles de ser superadas pero no por nada, sino por una valoración diversa. Se abre la posibilidad de un 'más allá' en tanto, justamente, esos valores del bien y el mal no representan ya el paraje axiológico último. En este sentido, Stevens remarca el problema de la trayectoria inversa: una genealogía que apunta a encontrar el verdadero fundamento de los valores morales, y que halla sus representantes centrales en Reé y Strauss, en una suerte de reducción de lo moral a lo biológico vía teoría darwiniana - en este sentido la burla nietzscheana: genealogistas-monos (Genealogisten-Affen) (cfr. STEVENS, 2003, p. 562 y ss.).
} 
a valor, resulta que 'el valor no le deja ser al ser' (2000b, p. 102), es decir, no permite salirse del plano óntico para alcanzar el plano del ser y así romper con la perspectiva metafísica. Ahora bien, según se marcó en el primer apartado, Nietzsche sí se pregunta por las condiciones de posibilidad de la representatividad: la ficcionalidad propia de toda perspectiva se da al hacer a la vida misma como algo opaco a toda posibilidad autorreflexiva - y por extensión, autovalorativa. Vida y voluntad de poder no se superponen: mientras la vida apunta al carácter mismo de opacidad y parcialidad, la voluntad de poder resulta una perspectiva particular que, como Nietzsche mismo afirma, no es sino una ficción más - lo cual halla directa consonancia con la noción de Herkunft foucaultiana.

Heidegger piensa la sentencia 'el valor no le deja ser al ser' desde el plano de la verdad - Nietzsche queda atrapado en lo óntico, encubriendo su verdad al no interrogar por sus condiciones de posibilidad. Desde la lectura aquí desplegada es posible establecer un corrimiento respecto al sentido que Heidegger postula. No es que Nietzsche no vea las condiciones de posibilidad, sino que les otorga otro valor que el que Heidegger les da: no son pasibles de fungir como fundamento, no permiten ser la base desde la cual desplegar una verdad. Así, 'el valor no le deja ser al ser' ha de leerse - desde una perspectiva que no equipara vida y voluntad de poder - no desde la verdad sino desde el valor que dicha verdad presenta.

Este corrimiento en la lectura de las relaciones entre verdad y valor dispone a Heidegger y Nietzsche como enfrentados respecto a la noción de nihilismo. Si para Heidegger la historia de la cultura occidental es aquella del olvidar, encubrir al ser, siendo Nietzsche su último - y máximo - exponente, para Nietzsche, desde la lectura aquí desplegada, la historia de la civilización occidental - desde Sócrates y Platón, pasando por el cristianismo y llegando a la ciencia moderna - es la del olvidar o encubrir el carácter eminentemente ficcional de toda verdad. Desde este punto de vista Heidegger no es sino otro metafísico, un retorno más a los valores vitales descendentes, que busca pensar al devenir del mundo en términos de verdad y ser. Al buscar la verdad no hay creación posible desde Heidegger: lo que hay es repetición de estructuras, recubrimientos de elementos ya dados. Y esto lo hace un nihilista: "Voluntad de verdad' como impotencia de la voluntad de crear.'(NIETZSCHE, 2008, 9[60], p. 250). El nihilismo así queda signado en torno al valor o en torno a la verdad: la falta de querer (crear) en Nietzsche, frente a la falta de verdad como ocultamiento y desocultamiento en Heidegger.

Como comenta Vermal, '[l]a lectura de Heidegger no es una interpretación usual que intentaría presentar 'lo que Nietzsche realmente dijo', sino que lo interpreta desde un proyecto $(\ldots)^{\prime}(2010$, p. 98). En términos de dicho proyecto - que busca poner a Nietzsche como el último metafísico - Heidegger realiza una serie de operaciones discursivas: suelda las nociones de voluntad de poder y vida, lo cual permite disponer una diferencia de naturaleza entre el devenir y la permanencia - el 'Arriba y Abajo' platónico, invertido; oblitera la lectura nietzscheana de las condiciones de posibilidad de la representación, lo cual lo habilita para establecer que no hay posibilidad de inquirir fundadamente desde Nietzsche sobre la naturaleza de la verdad. La articulación de ambos elementos dispone un panorama en el cual Nietzsche olvida el plano del ser para disponer inválidas diferencias ónticas (o más bien, diferencias que se quieren postular como más de lo que son, pues no hacen sino darse en lo meramente óntico): el Arriba y Abajo, desde la vida como ser en sí. Así, aquello que le falta al pensamiento nietzscheano (pensar el plano ontológico como condición de posibilidad respecto al óntico, pensar las condiciones de posibilidad de la representación en términos de verdad) es falazmente reconstruido en su diferenciación en el plano de los entes - y así, el Arriba nietzscheano como devenir es el mundo verdadero, y el Abajo como permanencia es la pura apariencia. 
Desde el análisis por nosotros desplegado, las condiciones de posibilidad de la representación sí han sido consideradas por Nietzsche; así, no es que falte algo, sino que la manera de considerar la relación entre la representación y sus condiciones de posibilidad resulta diversa. No hay una falta, sino una diversidad en la valoración: la ficcionalidad en Nietzsche no otorga ninguna autenticidad respecto a las múltiples configuraciones posibles - y por ello, el ámbito de resolución implica lucha. Nietzsche considera a la verdad desde la perspectiva de condición de posibilidad de la representación, y la valora como decadente: no conduce sino al nihilismo, al no querer crear. Y esto es lo que Heidegger, justamente, busca borrar en el sesgo que realiza de la lectura nietzscheana: que el valor de la verdad como condición de posibilidad resulte nihilista. Así, desde la perspectiva del valor Nietzsche resulta metafísico para Heidegger no por no ver el ser - por ocultarlo - sino por explícitamente desvalorizarlo como fundamento. Lo que Nietzsche hace es romper no al ser, sino al fundamento - a la posibilidad de señalar un criterio de autenticidad ${ }^{11}$. Desde el punto de vista de Nietzsche, Heidegger es el metafísico al redisponer al fundamento - incluso si dicho fundamento es el ocultamiento, la pregunta, el cuestionamiento. La postura heideggeriana da curso a una vida descendente, a la verdad del ocultamiento, que cierra el conflicto entre perspectivas al poner una en un plano diverso - al hacerla auténtica. Ser profundos en la superficie implica ${ }^{12}$, por el contrario, poner a toda perspectiva en un mismo plano - y desde allí, ponerlas en conflicto.

Discursivamente, la operación heideggeriana de obliteración cobra sentido táctico en tanto allí no hay discusión argumentativa sino valorativa: se batalla en torno al valor mismo de la verdad. Al borrar la perspectiva nietzscheana respecto a las condiciones de posibilidad, lo que Heidegger busca es transformar una discusión valorativa - en función de dos perspectivas de la posibilidad de pensar la verdad en términos de fundamento - en una argumentativoanalítica - en función de una falta de análisis de dichas condiciones por parte de Nietzsche que volvería su análisis parcial, y por ende inválido. En términos del análisis aquí desarrollado entonces, no hay una perspectiva en falta respecto de la otra sino que - a la manera en que es concebido el plano de fuerzas nietzscheano - ambas perspectivas presentan una misma entidad argumental, siendo variantes en cuanto al valor otorgado a la verdad - y por ende, entrando en pugna por lograr la preeminencia respecto a lo que han de ser la vida, el mundo, el arte, la creación - el futuro.

\section{Referencias}

CONSTANTE, A. A propósito del Nietzsche de Heidegger. Signos filosóficos, Méjico, 6, 2001. p. $85-112$.

DAVIS, M. E. Martin Heidegger: Key Concepts, Durham: Acumen, 2010.

FOUCAULT, M. Nietzsche, la généalogie, I' histoire. Hommage à Jean Hyppolite, París: PUF, 1971. p. $145-172$.

\footnotetext{
${ }^{11} \mathrm{Al}$ respecto resulta interesante la contraposición entre el 'gran arte' heideggeriano que implica 'autenticidad' (cfr. HEIDEGGER, 2003, p. 39 y ss.) desde la cual se da, como señala Veraza Tonda, la 'puesta en obra de la verdad' (2012, p. 109), frente al arte 'irónico, ligero, fugitivo, divinamente desenvuelto, divinamente artificial' que propone Nietzsche (2001, p. 14), frente al cual la voluntad de verdad implica 'mal gusto' (p. 15).

12 Según Nietzsche los griegos eran 'superficiales... ipor profundidad!' (2001, p. 18). La profundidad nietzscheana, la mirada que se alarga y que es capaz de ver en lo profundo, muestra que allí no hay nada que ver -es decir, no hay nada válido en buscar la verdad, no hay nada que valga como fundamento.
} 
HEIDEGGER, M. Nietzsche I. Trad. Juan Luis Vermal. Barcelona: Destino, 2000a.

HEIDEGGER, M. Nietzsche II. Trad. Juan Luis Vermal. Barcelona: Destino, 2000b.

HEIDEGGER, M. Gesamtausgabe 87 - Nietzsche: Seminare 1937 und 1944. Peter von Ruckteschell (ed). Barcelona: Herder, 2004.

HEIDEGGER, M. Ser y tiempo. Madrid:Trotta, 2012.

HEIDEGGER, M. On the Origin of the Work of Art: First Version. Heidegger Reader, Indiana Univ. Press, trad. Jerome Veith, 2009. p. 130-150.

HEIDEGGER, M. Zum Ereignis-Denken (GA 73.1). Peter Trawny (ed.), Frankfurt a/M: Vittorio Klostermann, 2013.

KRELL, D. Art and Truth in Raging Discord: Heidegger and Nietzsche on the Will to Power. Martin Heidegger and Literature 4/2 (1976), Duke Univ. Press. p. 378-392.

LÖWITH, K. Les implications politiques de la philosophie de l'existence de Martin Heidegger. Les temps modernes, París, 14, 1946. p. 342-374.

NIETZSCHE, F. Fragmentos Póstumos. Madrid: Tecnos, 2008

NIETZSCHE, F. Más allá del bien y del mal. Madrid: Alianza, 2007a.

NIETZSCHE, F. El crepúsculo de los ídolos. Madrid: Alianza, 2007b.

NIETZSCHE, F. Genealogía de la moral. Madrid: Alianza, 2000.

NIETZSCHE, F. La ciencia jovial. Madrid: Biblioteca Nueva, 2001.

NIETZSCHE, F. Sobre verdad y mentira en sentido extramoral. Madrid: Península, 2003.

STATEN, H. The Problem of Nietzsche's Economy. Representations, n. 27, Univ. of California Press, 1989. p. 66-91.

STEVENS, J. On the Morals of Genealogy. Political Theory, Vol. 31, n. 4, Sage Publications, 2003. p. 558-588.

VERAZA TONDA, P. El pensar del Ereignis de Heidegger como otra fenomenología. Método e inicio del camino. Franciscanum 165, Vol. Lviii, 2016. p. 89-116.

VATTIMO, G. Diálogo con Nietzsche. Buenos Aires: Paidós, 2002.

VÉLIZ RODRIGUES, S.; MONTAGUD, Micó, A. Nietzsche desenmascara a Heidegger. El genio maligno, 15, 2014. p. 21-54.

VERMAL, J. L. Acerca de la inversión del platonismo en Nietzsche y Heidegger. Estudios Nietzsche, 10, 2010. p. 97-111.

ZENGOTITA, A. Nietzsche y Darwin: el valor de un discurso como ficción útil. Estudos Nietzsche, 7/2, 2016, p. 56-79. 


\section{Sobre o autor}

\section{Alonso Zengotita}

Doctor y profesor en Filosofía por la Universidad de Buenos Aires (UBA), docente de la Facultad de Psicología de la UBA, becario postdoctoral del Conicet. Trabaja en el área de filosofía contemporánea, especialmente alrededor de la temática de la biopolítica y la interrelación entre filosofía y psicoanálisis.

Recebido em: 14/02/2021.

Aprovado em: 20/06/2021.
Received: $14 / 02 / 2021$.

Approved: 20/06/2021. 